\title{
Notas um pouco céticas sobre hipertexto e construção de sentido
}

\section{A little bit skeptic notes about hypertext and sense construction}

\author{
Sírio Possenti* \\ Um palaferneiro recomendava a um freguês um cavalo \\ de sela. "Se você partir nesse cavalo às quatro da \\ manhã, estará em Pressburg às seis e meia”. - "E o que \\ eu vou fazer em Pressburg às seis e meia da manhã?" \\ Citado por Freud em Os chistes e sua relação \\ com o inconsciente.
}

\begin{abstract}
RESUMO
O objetivo deste trabalho é contrapor-se a um discurso de maravilhamento em relação ao hipertexto. Tenta-se mostrar que parte desse otimismo deriva de análise equivocada dos textos "tradicionais" e de seus suportes. Tenta-se mostrar que o efeito mais positivo das teorias sobre o hipertexto é deixar mais claro que os textos tradicionais são menos lineares e menos dependentes do autor do que se supõe nesta contraposição.

Palavras-chave: hipertexto, sentido, autoria, leitura.
\end{abstract}

\begin{abstract}
The objective of this work is to pit itself against a certain wondering discourse in relation to hypertext. It tries to show that part of that optimism is produced by misunderstood analysis of "traditional" texts and their stands.

* Doutor em Lingüística pela Unicamp. Professor de Língüística do IEL/Unicamp.
\end{abstract} sirio@iel.unicamp.br 
It tries to show that the most positive effect of theories on the hypertext is to put on evidence that traditional texts are less linear and less dependent of author than can be supposed in this pitting.

Key-words: hypertext, meaning, autorship, reading.

\section{Duas histórias, como introdução}

Queria começar esta fala com episódios que, aparentemente, têm pouco a ver com nosso tema. O primeiro certamente depõe contra mim, mas não só. Certo dia, há alguns anos, ao contrário do que costumo fazer, acabei me insinuando na conversa de três colegas, animados conhecedores dos segredos da navegação via internet, logo que a novidade apareceu. Não lembro bem, mas acho que eu nem manejava ainda meu primeiro PC, do qual não tenho nenhuma saudade. Ouvia atentamente as aventuras daqueles três heróis, ocorridas na noite anterior. Todos tinham ficado em casa, mas, cada um de sua casa, quase miraculosamente, para mim, tinha penetrado em arquivos de bibliotecas distantes e descoberto referências inimagináveis. Lembro vagamente que um deles contou eufórico que, sobre seu tema de pesquisa, tinha identificado cerca de duzentos títulos, só em uma das bibliotecas acessadas. Foi então que eu caí na besteira de perguntar, com olhos esbugalhados, diante de tal pletora de bibliografia, quantos tinha conseguido ler naquela noite. Ele, mais incrédulo do que eu, respondeu que não tinha lido nenhum, que não era assim que a coisa funcionava. Então eu disse, para não dar o braço a torcer, que eu, naquela mesma noite, modestamente, e pelos métodos correntes, tinha lido um artigo.

Gosto muito de A formação do espírito científico, de Gaston Bachelard. Mesmo não sendo um livro de piadas, ele já me fez rir muito. Claro que esse riso só é possível neste final de século, e mesmo assim não ocorre com todos os leitores. Por exemplo, dei boas risadas quando li pela primeira vez o capítulo II, que se chama "O primeiro obstáculo: a experiência primeira”. Nele, são contados vários episódios, ocorridos na história das ciências naturais, a propósito, por exemplo, do trovão e da eletricidade. É em relação a esta que gostaria de trazer uma ou duas citações colhidas naquele livro, citações que, como disse, me fizeram e ainda fazem rir. Os 
fenômenos elétricos causavam espanto e se prestavam a uma exploração pseudo-científica que, segundo Bachelard, constitui um obstáculo ao conhecimento, porque se considerava a experiência, mas não a teoria, os fatos, mas não as leis. Vejam-se as seguintes transcrições:

Cada físico repetiu as experiências, todos queriam sentir a emoção... O marquês de $\mathrm{X}$ tem, como se sabe, um belo gabinete de física, mas a Eletricidade é sua paixão e, se o paganismo ainda vigorasse, ele decerto ergueria altares elétricos. Ele sabia quais são minhas preferências e não ignorava que também sou fã da Eletromania. Convidou-me, portanto, para um jantar onde estariam presentes, segundo ele, os medalhões da ordem dos eletrizantes e das eletrizantes (S.n.a. Histoire général et particulier de l'electricité, apud BACHELARD, 1938, p. 41).

Ainda mais interessante, a meu ver, é o seguinte jantar elétrico do grande Benjamin Franklin. Segundo o mesmo livro, Franklin e seus amigos

...mataram um peru por choque elétrico, assaram-no num espeto elétrico, diante de um fogo aceso por meio da garrafa elétrica: a seguir, beberam à saúde de todos os célebres entendidos em eletricidade da Inglaterra, Holanda, França e Alemanha, em copos eletrizados, e ao som da descarga de uma bateria elétrica (Priestley, Histoire de l'electricité, apud BACHELARD, 1938, p. 42).

Conto estas coisas e acrescento que tinha imaginado fazer aqui uma exibição de gala, do tipo desse jantar elétrico. Pensei em trazer um lap-top e um telefone celular, pedir que se montasse aqui - deve haver, todo mundo tem um - um data show. Assim, poderia não só falar alguma coisa sobre o hipertexto, mas mostrar um deles, ou mesmo vários, de variados tipos, até mesmo para deixar mais ou menos claro que eles não são todos iguais. O efeito seria ainda mais impressionante, eu imaginava, por ser provocado por mim, um cético meio caipira.

O que disse até aqui fica reservado, no sentido que esta palavra tem nas receitas culinárias, para ser retomado no final. 


\section{Primeiras experiências}

Quando ouvi falar de hipertexto pela primeira vez, eu, que tenho a mania, o vício ou a virtude (não sei mais) da literalidade e, gosto de imaginar, um certo senso de humor, pensei em primeiro lugar que se tratava de um texto muito grande; em seguida, que se tratava de um texto muito bom (minhas hipóteses sobre o que um computador poderia fazer, antes de ter certeza de que faz estritamente o que mandamos que faça, eram absolutamente infantis). Minhas primeiras experiências de visitas a sites me convenceram quase cabalmente de que a segunda das minhas suposições infantis raramente se confirma. Os melhores textos disponíveis na rede, eletronicamente, ainda são os textos que foram escritos para circularem em forma de livro - a Enciclopédia Britânica e a fortuna crítica de Dante, para tomar dois exemplos clássicos. O outro lado desta experiência, que me levou à mesma conclusão, ocorreu em virtude da necessidade de pesquisar alguma coisa sobre água, por motivos mais ou menos sigilosos, no segundo semestre de 1999. Nesta ocasião, quase fui levado a concluir - só não o fiz porque sou inimigo visceral das generalizações por amostragem, mesmo quando dão certo (trata-se de medo do fantasma de Hume) - que praticamente todos os cidadãos que não têm um bom texto - talvez não conseguissem uma editora que os publicasse - têm um texto circulando pela internet. Estou excluindo da classe dos que julgo maus textos, evidentemente, aqueles textos que foram postos também na internet depois de já serem textos à moda antiga, quero dizer, impressos ou facilmente imprimíveis no papel. Tanto que, pouco modestamente, imaginei uma profissão alternativa para mim, quando viesse a me aposentar: copidescar textos eletronicamente distribuídos.

Quando ouvi falar dos trabalhos de Chartier pela primeira vez, o que ouvi foi que ele teria tentado mostrar que a leitura dos textos é afetada pelo suporte. Ou seja, que não lemos da mesma maneira um rolo de papiro e um livro com a conformação mais ou menos conhecida de todos. E fui de novo atacado pelo mesmo vírus da literalidade e fiquei me perguntando que raios de poder tem o suporte material do texto para fazer com que um leitor "interpretasse" de maneira diferente o mesmo texto pelo fato de ele estar copiado num papiro ou impresso em papel por uma máquina que imprimiu centenas ou milhares de outros exemplares exatamente iguais ou rodando verticalmente na tela de um computador. Me perguntava, por exemplo, em que medida alguém atacado de uma insônia renitente, indo a seu escritório, 
de madrugada, e tomando um escrito ao acaso, digamos, o Livro de Jó, descobriria um certo tipo de sentido (digamos, um discurso conformista), se manipulasse um papiro, e um outro tipo de sentido (digamos, um discurso de revolta contra as injustiças, mesmo que do outro lado estivesse o poderoso Javé), se tivesse à mão um exemplar mais ou menos típico da Bíblia editado pela Ave Maria. Como eu era bobo!

Depois, indo ao próprio autor, descobri que não era disso que se tratava - ou seja, achei que o discurso de Chartier não era o discurso dos chartietes. Achei que CHARTIER $(1994 ; 1997)$ defende de fato a hipótese de que não lemos do mesmo modo num papiro, num livro ou numa tela de computador (se este fosse um hipertexto, eu talvez colocasse aqui, em cor verde, a marca de computador que uso, e meu eventual leitor (terei algum?) clicaria sobre ela para descobrir não de que tipo de máquina se trata e em que medida ela ajuda ou prejudica a leitura, mas o nome de uma loja onde poderia efetuar uma compra... e talvez eu estivesse aqui patrocinado por esta marca). Mas, para ele, "ler de outro modo" não significa necessariamente atribuir sentidos diversos, e sim outra coisa, muito diferente, que só pode parecer a mesma porque se designa pela mesma palavra, leitura. A saber: ler de outro modo significa, por exemplo, poder ou não poder efetuar atividades mais ou menos simultâneas como fazer anotações à margem do livro - coisa que se pode fazer em livros que têm margens e não se pode fazer em papiros (nem em livros que não têm margens, diga-se de passagem), até porque aqueles são freqüentemente de propriedade particular e estes pertencem tipicamente à biblioteca de um convento ou de um palácio ou a um museu. Ou então: ele imagina que a circulação eletrônica dos textos pode vir a matar a profissão de crítico (mas talvez os jornais já a tenham feito morrer de indigência - as críticas de hoje são de fato outros tantos releases).

Em resumo, penso que a questão da mudança de sentido produzida pela diferença de suporte passa longe da questão da decifração de um texto, da descoberta de seu tema, de suas relações intertextuais, e, evidentemente, ainda mais longe do sentido como sendo a intenção, dada a conhecer direta ou indiretamente, de um autor individual identificável, como se o autor fosse o locutor que está a nossa frente num bar, falando de bebidas típicas ou de preferências eleitorais.

De uma certa forma, o que Chartier afirma a propósito das diferenças de leitura implicadas pelo suporte tem versões menos radicais e correntes. Por exemplo, é mais ou menos comum dizer que crônicas de jornal reunidas e postas em livro adquirem um sentido diferente. Também acho. Desde 
que seja esclarecido o que significa aqui a palavra sentido. Penso que uma coisa é conferir à crônica um ar menos passageiro, caráter que o livro dá e o jornal não dá, ou até tira, e outra coisa é imaginar que a lemos de outra forma, no sentido de que lhe atribuímos outros "conteúdos" - o que pode ocorrer, por exemplo, mais facilmente como conseqüência do passar do tempo, porque esse fator produz recepções diferentes, o que poderíamos chamar de efeito Ménard, do que como conseqüência da mudança de suporte. $\mathrm{O}$ efeito da leitura de debates e ataques políticos pela imprensa no tempo de D. Pedro I é grande em relação ao que pensávamos que eram a imprensa e a sociedade da época. Mas ler esses textos nos próprios jornais ou numa seleção apresentada em livro não produz efeitos muito diferentes.

\section{Por que lemos como lemos}

A despeito da impressão que pode causar o que venho dizendo, não estou querendo dar a entender que penso que o hipertexto não significa novidade alguma ou não implica diferenças relevantes, ou, principalmente, que não implicaria mudanças de atitude ou de atividades. Especialmente, não estou querendo dizer que as novidades ou diferenças que ele implica não sejam capazes de produzir efeitos extremamente relevantes até mesmo em relação ao sentido, mesmo que esta palavra seja tomada no sentido mais estrito de decifração de um texto. O que estou querendo dizer é que é minimamente necessário dar-nos conta de que certas expressões podem estar fazendo pensar que a mudança de suporte é suficiente para alterar o texto, tornando central, sem razão, a meu ver, um elemento que até recentemente era de fato desconsiderado ou considerado absolutamente secundário no debate sobre o sentido.

De fato, a tradição, mais ou menos alternadamente, atribuiu a diversos ingredientes a chave da descoberta dos sentidos de um texto. Em primeiro lugar, à própria língua como "código". Pensemos não nas interpretações de obras literárias, ou, mais radicalmente, dos sonhos, mas, por exemplo, na decifração da pedra de Roseta, que fez a glória de Champollion. Todos sabemos, evidentemente, que ler não é exatamente isso, ou apenas isso, mas podemos ser tentados a esquecer de que é também isso, seja no caso de o texto ser acessível por computador, seja no caso de um pequeno recorte de jornal casual-mente disponível num despossuído banheiro de ro- 
doviária, que informe, digamos, sobre a última hipótese da polícia sobre o paradeiro do juiz Lalau. Com esse lembrete, o de que a leitura ainda passa pela decifração dos textos, quero dizer apenas que, freqüentemente, temos transformado sem cuidado o sucesso de vendas da coleção "Os pensadores" com um inexplicável surto de filosofia no país, ao invés de imaginar mais rasteiramente que ainda são mantidos velhos padrões de decoração das salas de estar.

Sabemos que, quando o texto não é transparente - e sabemos também que ele nunca é transparente -, apelamos sucessivamente para certas estratégias de interpretação que vão além das estratégias fornecidas no processo de alfabetização. A filologia, e também, de alguma forma, as modernas teorias textuais marcadas pelos princípios mais gerais da pragmática, imaginava poder encontrar uma chave de leitura na decifração do projeto do autor. Ou seja, depois e além do que nos informa um texto como construto meramente lingüístico, apelávamos para outra instância, o autor (entendido de mais de uma forma, vale lembrar, o que contribui para tornar controversa e multifacetada até mesmo esta estratégia, porque uma teoria que valorize o autor não é a mesma segundo a psicologia, a lingüística, a sociologia, a antropologia etc. envolvidas).

$\mathrm{O}$ autor entrou em crise com o estruturalismo, digamos. Quando leio em textos sobre hipertexto que este de uma certa forma reduz o papel do autor e permite assim maior liberdade ao leitor, fico me perguntando em que penumbra ficou, por exemplo, a tese de Barthes, que é até mais radical do que esta mais recente, além de ser notoriamente muito anterior, não só a esta formulação, mas também ao próprio hipertexto. Ou seja, o autor morreu há muito tempo (pelo menos, sua morte foi anunciada, e nunca saberemos se esta era uma notícia verdadeira ou se era uma forma de despiste), embora seu fantasma continue a assombrar velhos redutos, de dia e de noite. Aliás, foi com a morte do autor, mas não sei se por causa dela, que o texto foi erigido, no seu lugar, em ingrediente fundamental nas estratégias de interpretação. Os diversos desenhos do estruturalismo e do new criticism atestam sobejamente esta tese. Assim, não foi o hipertexto que reduziu o autor a seu modesto lugar, mas uma concepção de linguagem que, por várias vias, imaginou poder mostrar que, fosse lá o que fosse que o autor quisesse dizer, seu texto o ultrapassaria ou o trairia, seja porque estivesse submetido a regras de gênero, seja porque o autor poderia estar submetido, sem saber, a desejos de dizer que não controlasse (as obras de Propp e as incursões da psicanálise pela literatura, em todos os sentidos, completaram o serviço, na esteira do estruturalismo). 
No entanto, a tentativa de explicitar de uma vez por todas os sentidos dos textos, exibindo suas estranhas, reinterpretadas como metáforas ou estereótipos (porque a decifração dita literal era obviamente insatisfatória), foi mal sucedida. Foram os próprios campeões do estruturalismo que decretaram a falência da empreitada. O caso de Umberto Eco é exemplar. Sua frase de efeito segundo a qual o "autor deveria morrer depois de escrever, para não perturbar o caminho do texto", destinava-se a evitar uma estratégia interpretativa que apelasse para o autor; em seu caso, destinou-se a evitar que lhe perguntassem o que tinha querido dizer em determinadas passagens, pelo menos no caso de o livro ser um romance (Eco se referia a episódios relativos à recepção de $O$ nome da rosa). Esta declaração vai na mesma direção da tese da morte do autor (mas como um autor poderia morrer? Com a morte do escritor? Que confusão!). Outra declaração de Eco poderia ser considerada uma defesa da tese da centralidade do texto ("o texto está aí, e produz seus próprios sentidos"). Mas ele é conhecido como o defensor dos limites para a interpretação, da intentio operis, para além da intentio auctoris e da intentio lectoris. O caso é bom para nos prevenir contra a associação de discursos a pessoas, a locutores ou mesmo a autores. O que aqui importa assinalar é que a colocação do texto no centro da questão não significou a tirania do texto, porque essa tese só seria possível fazendo de conta que o texto está sempre sendo interpretado no sentido em que foi interpretada a inscrição contida na pedra de Roseta e, paradoxalmente, no caso, não haveria um problema de leitura.

Assim, o terceiro ingrediente ao qual apelamos, imaginando que ele poderia resolver nosso problema (de decifração de um texto, lembremos), é o leitor. Barthes já assinalara que a morte do autor conduzia o leitor ao centro da cena (não para ler como quisesse, pois que sempre há algo de pedra de Roseta em qualquer livro, mesmo em textos surrealistas), porque o leitor é uma espécie de máquina que associa o que lê ao que já leu, ao que pensa a partir do que já leu etc. O leitor de Barthes tanto pode ser caracterizado por critérios mais "objetivos" - ele aproxima obras de obras segundo uma certa tradição - como por critérios mais "subjetivos" - ele aproxima obras de obras ou passagens de passagens ou palavras de palavras por associação, no sentido tanto da associação livre e quase indiossincrática quanto da que se dá com base em sua trajetória particular de leitor, que pode estar mais ou menos de acordo com a tradição.

A sensação que tenho é que, em decorrência de estudos como os de Chartier, foi agregado um quarto ingrediente a esse conjunto de critérios, destinados a servir de guia para a leitura. Este quarto ingrediente seria o 
suporte - livro, jornal, revista, e-book, computador, internet. Gostaria de dizer, mesmo correndo sérios riscos - risco de estar equivocado quando à interpretação do que ouço e leio e também risco de estar defendendo teses indefensáveis ou apenas simplórias -, que está havendo grande confusão no que se refere à leitura como atividade que envolve muitas outras subdivisões quase institucionais (comprar, vender, editar, controlar o autor, considerar o prestígio dos grandes leitores, ler anotando ou na espreguiçadeira etc.) e como atividade de apreensão de um certo discurso (por exemplo, reler Édipo Rei para conferir se a interpretação de Freud é mais ou menos defensável que a de Foucault ou que a de Deleuze \& Guattari). Creio que devemos distinguir claramente estas duas atividades e seus desdobramentos, a despeito de serem designadas pela mesma palavra. Temas como "O estado da leitura no Brasil" ou "A recepção de Sartre" podem ser expressões absolutamente ambíguas, e não esclareceríamos nenhum problema se não distinguíssemos o fato de que lemos muito ou pouco dos critérios pelos quais as interpretações são umas ou outras - a não ser que creiamos piamente que quantidade gera qualidade ou que a questão da qualidade sequer interessa na discussão sobre leitura.

\section{Indo finalmente ao tema}

Creio que é hora de enfrentar o que é dito sobre hipertexto nas questões cruciais, as que afetem leitura e sentido de alguma forma. Creio que essas questões são as que mencionei acima, independentemente do que é dito quando tratamos de hipertexto, a saber: autor, leitor, texto, suporte. Mais ou menos curiosamente, é em relação ao texto que aparecem teses que se apresentam como sendo mais ou menos novas ou que especificam aspectos constitutivos, como, por exemplo, em relação à relevância e à linearidade. Não tenho encontrado maiores especificações quanto à noção de autor, como tradicionalmente é feito alhures quando o foco é a autoria, quando são reconhecidos traços diferenciadores segundo uma certa ordem dos textos. Essa função seria de um tipo se tratasse de textos científicos, de textos literários ou de outros textos, como os de caráter jornalístico ou as coleções de piadas, tenham ou não um tema específico. 
Vejamos, em primeiro lugar, a questão do autor. Este tema é certamente o menos bem discutido na literatura sobre hipertexto, se posso me louvar no que li em MARCUSCHI (1999) e XAVIER (2000), e na fidelidade às referências por eles mencionadas. Neste, a novidade seria que a tecnologia do hipertexto permite que qualquer um publique suas idéias, sem passar pelo que Foucault provavelmente chamaria de sociedade de discurso, ou seja, sem passar pelo crivo do atual sistema editorial. Sabemos das constrições existentes para a publicação de um livro, e mesmo de um artigo, científico ou jornalístico, ou mesmo de uma carta de leitor a um jornal ou revista de variedades. Mas, imagino, não podemos ainda nos empolgar com a possibilidade infinita de publicação. Mais ou menos como ocorre hoje pelos meios tradicionais, as personalidades que publicam pela internet continuam sendo os escritores, os artistas e os corajosos de várias extrações, sendo que todos eles devem dispor de recursos para financiar (às vezes, para pagar quem escreva por eles) seu espaço ou utilizar um espaço público, pago pelo seu, o meu o nosso dinheiro, para retomar uma expressão do presidente do Banco Central. Como em outros casos, esta nova situação permite revisitar o que ocorre hoje nos suportes de papel. Creio que, se analisarmos o que é impresso, estaremos longe da sacralidade do autor, aludida no texto de Xavier. Muitos autores conseguem publicar porque são outra coisa: artistas, paraplégicos, ex-drogados, homossexuais, atletas, kardecistas, cozinheiros, afetados recentemente por uma doença incurável etc., mesmo que não tenham uma obra. Vejam-se os romances de Jô Soares, por exemplo, e as já várias vidas de ex-drogados ou vítimas de erros médicos e artistas de segunda, como Ratinho e Adriane Galisteu, que editaram seus livros e obtêm com eles algum sucesso ou pelo menos um olhar mais piedoso ou mais respeitoso. Quero dizer: estamos confundindo a queda de um tipo de barreira com sua ausência pura e simples.

Curiosamente, no entanto, não discutimos a questão da autoria dos hipertextos considerando minimamente sua natureza diversa. Fora do espaço do hipertexto, são diferentes os critérios pelos quais consagramos um romancista, um poeta, um filósofo, um cientista, um jornalista, um organizador de coleções de piadas etc. Tomemos esse caso para exemplo: um humorista fará mais sucesso (consideramos usualmente que tem mais direito de fazê-lo) organizando um livro de piadas do que um professor de lingüística ou um físico. Se não fizermos essas distinções, desperdiçaremos certamente a ocasião de compreender o que é e como funciona um autor, não só no hipertexto, mas também no mundo do papel. 
Em Marcuschi, ou melhor, nos autores que cita, a questão da autoria passa por outro caminho: indiretamente, o autor é concebido como aquele que organiza a sequiência textual. Seria por isso que o hipertexto acabaria atribuindo ao leitor um papel similar ao do autor, na medida em que caberia em grande parte ao leitor organizar a seqüência do que vai ler (clicando ou não palavras-chave, por exemplo, ou seja, indo ou não a um outro espaço, e tendo ido, decidir se volta ou não ao texto como o autor o teria disposto ou imaginado). Assim posta, diria que é uma forma de tematizar apenas uma das funções do autor e do leitor, nem sei se a mais relevante. Para o autor, essa função seria a de organizar um texto em sequiência e o de assinalar quais os desvios e subdesvios que podem ser relevantes. Para o leitor, e nesse sentido ele seria co-autor, a de decidir se lê na mesma sequiência ou se adota outras estratégias e outros caminhos e quais seriam eles. Não consigo, a esta altura, não mencionar Machado de Assis, que dá a seu leitor sugestões como as seguintes: "Se o leitor não é dado à contemplação (...), pode saltar o capítulo; vá direto à narração". Machado, como sabemos, escreveu isso a mão, em triviais laudas de papel, no final do século XIX...

\section{Texto e hipertexto}

A maior vantagem de ler sobre o tema do texto em trabalhos que caracterizam mais ou menos euforicamente o hipertexto é que cada vez fica mais claro que estamos lidando, ou podemos estar lidando, com uma noção absolutamente simplória de texto (e MARCuschi, 1999, deixa isso muito claro). Suponhamos, por exemplo, que se diga - é o que mais se diz - que o hipertexto se caracteriza pela não linearidade ("a não-linearidade é tida como a característica central do hipertexto", conforme podemos ler em MARCUSCHI, 1999, p. 24). À luz dessa afirmação, se ninguém ainda o tivesse feito, teríamos que nos pôr a campo para verificar de que coisas falam afinal quando dizem que um texto é linear. Muito comumente, o livro é dado como o protótipo de texto, a ser eventualmente superado pelo hipertexto, assim como o livro superou o rolo de papiro.

Seria certamente interessante ler as páginas de FOUCAUlt (1969), na passagem em que o autor põe em questão alguns dos conceitos tradicionais que colaboram para sustentar a idéia de unidade (contra a de dispersão). 
Além da noção de formação discursiva, o autor põe em questão a idéia de livro. Talvez pudéssemos dizer que ele mostra cabalmente que nosso conceito prototípico de livro (aquele que contém uma história ou uma exposição que tem começo, meio e fim) não resiste a algumas perguntas. Por exemplo, pergunta ele, uma enciclopédia é um livro? Ou o será cada volume dela? Mas a ordenação é alfabética... E os romances de Balzac: um livro, muitos? E a Bíblia? E um missal? Poderíamos ir além, evidentemente: como descrever os livros que contêm artigos, que se lêem em qualquer ordem? Como tratar hoje de obras como $O$ jogo da amarelinha? E, mais modestamente, dos livros que narram histórias em flash back? Que exigências formular a respeito de livros que só se sustentam se sua leitura considera todos os livros a que fazem referência?

Sobre a questão da relevância, noção tipicamente ligada à textualidade, mas também a qualquer conversação, valeria a pena, eu acho, fazer pelo menos uma pergunta. Havendo concordância sobre o fato de que a questão só é relevante na discussão sobre hipertexto na medida em que os desvios de rumo são propiciados por um simples clique numa palavra ou expressão destacada no texto, as perguntas a fazer seriam: com base em quais critérios a referida palavra ou expressão é escolhida para ser marcada/destacada? É uma escolha livre do autor? É efeito das pressões típicas da disciplina e/ou do gênero de texto? Por exemplo, é um artigo científico e o assunto é clonagem? Se for, não posso marcar um $e$ ou um é, mas posso fazê-lo se o assunto for gramática e não posso deixar de fazê-lo se estiver tratando de preposições e de verbos irregulares. Relevância, sabemos, não é uma questão simples. Talvez só pareça simples em relação a textos científicos ou de situações estereotipadas, porque então, aparentemente, a seleção é um efeito do tema, do script ou do gênero e seria a mesma para qualquer autor ou leitor. Mas, no caso, onde ficaria a atuação do autor e do leitor com suas intervenções relevantes? Outra pergunta, mais ou menos marginal, provocada pela visita a um hipertexto: se um autor é citado, se o leitor clica sobre este nome, o que esperará ver na outra tela? Um resumo da obra que tornou a menção a esse autor relevante (!!!) ou o endereço da Amazon ou da Sarai$v a$, acompanhado das dicas de compra por cartão de crédito (que dá em árvores, como se sabe...)?

Para evitar mais mal-entendidos, repito que não estou querendo dar a entender que não há nada de novo no front. Insisto apenas em dizer que não devemos ainda nos deslumbrar. Penso que a maior vantagem do hipertexto ainda é nos fazer entender melhor o que é um texto. Descobrimos que as propriedades do texto que seriam as opostas das do hipertexto só seriam 
propriedades dos textos mais banais. Ou seja, certas glorificações do hipertexto constróem um simulacro de texto mais ou menos insuportável e que não resiste à menor investigação empírica. Como me disse Ingedore Koch, numa conversa informal, em que o tema era essa nossa vinda ao Recife, o problema é que "o texto é um hipertexto". Subscrevo. Pelo menos, só sabemos ainda fazer textos com os recursos do hipertexto, assim como fizeram e ainda fazem muito rádio pela TV...

Finalmente, pensemos um pouco no leitor. Posso estar simplificando, mas me pareceu que o leitor que emerge dos textos sobre hipertexto é constituído um tanto paradoxalmente. Por um lado, ele é todo poderoso, pelo menos mais poderoso do que o autor, tanto que decide ir por aqui ou por ali segundo seus interesses pelos links que quer visitar. Mas, por outro lado, surge assim um leitor sem história ou sem interesses. Um leitor sem história é um leitor não só sem ideologia, mas também sem profissão, sem nenhuma pressão do mercado e das instituições, pressões que, acredito, o levam a fazer com as possibilidades do hipertexto aquilo que deve fazer de qualquer forma. O leitor com história, levado ao limite, é o leitor interpelado pela ideologia e submetido por sua formação discursiva, e, seja ou não patrulhado, lerá só o que pode ler, com algumas exceções e pequenas escapadas, independentemente dos meios que tiver a sua disposição. O leitor sem interesses parece um leitor que tem a sua disposição um tempo infinito, é um leitor em férias permanentes, que pode dispersar suas consultas ao bel-prazer dos impulsos imediatos.

Creio que a história nos mostra leitores diferentes, mesmo leitores de hipertextos. Provavelmente, exceto em certos momentos - solitários e chatos domingos de tarde -, os leitores lêem o que devem ler, seja em decorrência das tarefas que devem realizar, seja em decorrência de suas idiossincrasias, seja em decorrência de quais são os textos de prestígio. Assim, alguns visitarão páginas de sexo, outros, listas de bibliotecas. Na maioria dos casos, os leitores, guardadas as proporções, são ainda como os leitores de que fala Maingueneau: os jansenistas têm pequenas bibliotecas, porque a intertextualidade permitida por seu discurso é caracterizada pela concentração - Bíblia, Padres da Igreja, certos teólogos, alguns cientistas. Já os humanistas devotos possuem tipicamente bibliotecas numerosas, incluindo alguns filósofos pagãos, por exemplo. Os visitadores de links, creio, são parecidos. Conheço alguns: os que só vão atrás de literatura, os que sabem onde encontrar notícias sobre recentes descobertas da física, os que lêem tudo sobre vestibulares ou sobre esporte ou receitas culinárias etc. Claro que todos, de vez em quando, visitam um site que informa sobre comidas de 
cachorro ou verificam as novidades na área das ofertas sexuais, mas não esqueçamos que nos conventos antigos também liam pornografia quando os monges e freiras estavam dormindo, ou lendo, por sua vez, pornografia na celas. Os leitores sempre se dividiram, sempre tiveram mais de um interesse, mas estamos longe da hipótese do leitor cujo dia tem mais de 60 horas e cujos rendimentos lhe permitem ao mesmo tempo não trabalhar e pagar os custos que as visitas desabusadas aos hipertextos implica (manter um Speed ainda custa um bom dinheiro).

Seria interessante, certamente (desconheço se isso já foi feito), verificar como os leitores empíricos de hipertexto lêem de fato. Já disse que detesto generalizações, mas já ouvi depoimentos como os seguintes: na Internet, perdemos o dia inteiro, porque uma coisa puxa outra e no final do expediente nem lembramos mais o que tínhamos ido procurar. Essa forma de ler seria uma possibilidade extrema - teríamos um leitor não submetido aos controles institucionais, mais ou menos livre para dar vazão a suas preferências, um leitor que segue, de alguma forma, as associações quaselivres que o meio lhe permite. E que não precisa pagar a conta da linha telefônica. Mas ele só fará isso excepcionalmente. Logo será despedido por falta de eficiência.

O leitor do hipertexto, tal qual emerge dos textos que tratam dele, lembra menos o leitor de textos e mais o cidadão que está bisbilhotando numa livraria, que analisa livros, que se encanta aqui com uma figura na capa e ali com o acabamento do livro, depois vai à estante de sua preferência e começa a ler orelhas e a verificar preços para, em seguida, lamentar seus baixos rendimentos e o pouco tempo de que dispõe. No meio do caminho, faz muxoxos diante de algumas estantes, sejam elas as que expõem livros de auto-ajuda, sempre muito povoadas, sejam as de lingüística ou psicanálise, coisas que não leu e de que não gostou. Alternativamente, esse leitor lembra o adepto da leitura dinâmica, ou melhor, a piada de Woody Alen sobre seu curso de leitura dinâmica. Diz que vai indo bem, que leu Guerra e Paz em 4 horas. "É sobre a Rússia", é tudo o que tem a dizer.

Esse leitor de hipertexto nunca é apresentado como constituidor dos sentidos de um texto, na tensa interação com o autor, a obra (o texto) e tudo o que já foi dito sobre a obra ou seu tema. O leitor de hipertexto parece estar sempre lendo pela primeira vez, e ele precisa, assim, que lhe forneçam pistas muito claras, em cores, para saber em qual momento pode ou deve derivar do texto (trecho?) que lê para outro texto (trecho?), que, eventualmente, fornecerá informações a mais (aliás, quase sempre se trata de informações...), ou, se tiver menos sorte, lhe fornecerá o endereço de uma 
livraria ou a propaganda de uma escola de línguas. Como é que esse leitor sem enciclopédia pode ser apresentado como concorrente do autor? Só se ao autor também faltar de tudo. Acho que é porque sempre supomos que o autor de um hipertexto nunca será um tipo de Machado de Assis. No máximo, um tipo de Mário Prata.

Em resumo, supor que, no livro tradicional o autor era uma autoridade maior que o leitor significa, em geral, não especificar os diversos tipos de leitura, de texto e de autoria. Por outro lado, supor que o hipertexto é o reino do leitor é supor que no livro o autor decidia tudo, determinava como o texto seria lido. Sabemos quanto ambas as suposições foram questionadas e esmiuçadas. Não temos o direito de fazer essa discussão como se ela estivesse sendo inaugurada agora, como efeito das redes de computadores.

\section{Concluindo}

Suponhamos que o hipertexto venha a se revelar um fracasso, no que não creio. Pelo menos um serviço ele terá prestado. Permitir uma melhor compreen-são da natureza do texto. As metáforas computacionais permitiram esclarecer aspectos do funcionamento mais ou menos controlado e minucioso da mente humana. Eventualmente, a idéia de hipertexto pode tornar-se uma interessante metáfora, que exibiria um pouco mais claramente como constituímos e manipulamos textos, por um lado, mas, especialmente, como se move um leitor real, mais ou menos controlado, ao ler qualquer tipo de texto em qualquer tipo de suporte. Paralelamente, e esta é uma questão de outra natureza, mas intimamente relacionada à questão da leitura como um tipo de decifração, certamente o hipertexto proporcionará ocasiões para debater a questão da edição, dos direitos autorais, o lugar da crítica e a constituição ou queda dos cânones.

Por enquanto, parece que o que é efetivamente novo é apenas o suporte, que implica no depósito virtualmente disponível de textos de todos os tipos (a Biblioteca de Babel?), ao alcance de um usuário que tenha à disposição um computador mais ou menos comum e uma linha telefônica. A maior revolução que isso poderia vir a produzir seria decorrente do fato de que muito mais pessoas vão ler, e que, por exemplo, em países de cen- 
sura férrea, a liberdade maior de ler pode produzir não só novos sentidos, mas também mais liberdade política e de costumes.

Não sei se a questão mais importante que o hipertexto nos coloca se relaciona com a construção de sentidos. Se acharmos que isso é verdade, teremos que refazer nossas análises em todos os domínios em que a questão se pôs tradicionalmente, e não perder de vista, quando for o caso, os novos domínios em que a questão vier a se tornar pertinente. Ou seja, teremos que nos perguntar em que sentido mudam os sentidos das palavras, das unidades sintáticas, dos textos, e em virtude de quê: dos novos leitores, que os recebem precavidos, ou do contato, esperado ou não, canônico ou não, com numerosos outros e novos textos. Ou se é apenas o que não seria pouco, mas seria outra coisa - uma nova forma de circulação de textos, sendo que, lamentavelmente, os leitores continuam sendo os mesmos ou, o que seria lamentável, piores.

Para concluir, ocorre-me que seria certamente interessante ler, à luz do que é dito sobre hipertexto (o leitor que dê um jeito de encaixar isso no restante do texto), as primeiras páginas da biografia do Barão de Mauá escrita por Jorge Caldeira (Mauá, empresário do Império, São Paulo, Companhia das Letras,1995). Nelas, é descrita a rotina diária da personagem, especialmente depois de sua chegada à casa. O que vale a pena destacar é parte dessa rotina, ou melhor, duas: primeiro, a passada de vista em muitos jornais e revistas do mundo inteiro, para inteirar-se da notícias, políticas e econômicas, e das novidades nos campos que lhe interessavam (engenharia e siderurgia, por exemplo). Imaginemos o quanto essas notícias e produtos eram recentes, comparados com a noção atual de novidade de mercado. A segunda parte dessa rotina consistia na redação de vasta correspondência, necessária à implementação de seus interesses, tanto os políticos e os mais ou menos pessoais quanto os relacionados mais estritamente a decisões sobre a venda ou compra de ações de bancos e empresas estrangeiras etc. Em nosso tempo, sabemos que um funcionário, mesmo se não muito poderoso, pode quebrar um banco numa noite, fazendo maus negócios conectado on line com bolsas em funcionamento no outro lado do mundo. Nos tempos de Mauá, a decisão de desfazer-se ou não de algumas ações de uma empresa estrangeira, ou mesmo nacional, sediada em Manaus, por exemplo, demoraria algumas semanas para ser implementada, uma vez que era comunicada por carta ou requeria a presença física do negociador. Mas, mesmo assim, excetuada a questão do tempo e dos meios de transporte, vemos Mauá mergulhado num universo certamente mais complexo (hiperhipertextual...) que o da maioria das pessoas que têm a sua disposi- 
ção um poderoso $\mathrm{PC}$, mesmo que não padeçam com os problemas de lentidão das ligações telefônicas e com as quedas de energia. O que nos coloca de novo o velho problema das questões econômicas e de classe. A velha História.

Imagino que não deveria ser necessário explicar a epígrafe, a não ser pelo eventual deslumbramento diante de tantos textos disponíveis. O vendedor de computadores ou o propagandista da internet me diria, talvez, que, se eu me tornar um navegador, terei a minha disposição centenas de milhares de textos de lingüística, as últimas novidades dos últimos congressos e quase todas as bibliotecas do mundo. A resposta que eu lhe daria é mais ou menos óbvia. A não ser que passasse a curtir festas elétricas. Mesmo assim, creio, a quantidade de carne assada que eu conseguiria consumir continuaria sendo basicamente a mesma.

\section{REFERÊNCIAS}

BACHELARD, G. A formação do espírito científico. Rio de Janeiro: Contraponto, 1938. CHARTIER, R. A ordem dos livros. Brasília: Ed. da Unb, 1994.

CHARTIER, R. A aventura do livro do leitor ao navegador. São Paulo: Ed. da Unesp, 1997.

FOUCAULT, M. A arqueologia do saber. Rio de Janeiro: Forense Universitária, 1969.

MARCUSCHI, L. A. Linearização, cognição e referência: o desafio do hipertexto. Línguas, Instrumentos Lingüísticos, Campinas, n. 3, p. 21-45, 1999.

XAVIER, A. C. S. Hipertexto: novo paradigma textual? Disponível em: <http:// www.unicamp.br/ hytex> Acesso em: out. 2000.

Texto recebido em 22 jul. 2002

Texto aprovado em 26 ago. 2002 